\title{
Pendidikan kesehatan reproduksi terhadap peningkatan pemeliharaan organ kesehatan reproduksi pada siswa tunagrahita dan autisme
}

\author{
Yuliyanik* $^{*}$ \\ Sekolah Tinggi IImu Kesehatan Widyagama Husada Malang-Indonesia
}

\begin{abstract}
Introduction: Health education especially reproductive health education has a very important role in helping adolescent people with disabilities in maintaining their reproductive health. In adolescents with disabilities (mental retardation and autism), they are less responsive even do not know how to maintain their reproductive health, especially the health of their reproductive organs. Adolescents with disabilities need patience in providing this information, it must be continuous and in accordance with their understanding. Knowledge of reproductive health is very much needed by all adolescents, both normal adolescents and adolescents with disabilities. Method: This type of research is pretest-posttest observation. The technique used is total sampling. Data analysis using SPSS 16 with Wilcoxon test. Results: Statistical tests show the results of $p$ value = 0,000 , this value is smaller than the significance level used that is $5 \%$ or 0.05 , this means that there is an influence between reproductive health education with knowledge of reproductive organ health in retarded students and autism. Conclusion: Reproductive health education influences the health knowledge of reproductive organs in retarded and autism students.
\end{abstract}

\section{Keywords: reproductive health; mental retardation; autism}

\begin{abstract}
Pendahuluan: Pendidikan kesehatan khususnya pendidikan kesehatan reproduksi memiliki peran yang sangat penting dalam membantu remaja penyandang disabilitas dalam pemeliharaan kesehatan reproduksinya. Pada remaja dengan disabilitas (tunagrahita dan autisme), mereka kurang tanggap bahkan tidak mengetahui bagaimana menjaga kesehatan reproduksinya terutama kesehatan organ reproduksinya. Remaja dengan disabilitas perlu ketlatenan dalam memberikan informasi tersebut, harus terus menerus dan sesuai dengan pemahaman mereka. Pengetahuan tentang kesehatan reproduksi sangat diperlukan oleh semua remaja baik itu remaja normal maupun remaja dengan disabilitas. Metode: Jenis penelitian ini dengan observasi pretestposttest. Teknik yang dipakai total sampling. Analisa data menggunakan SPSS 16 dengan uji Wilcoxon. Hasil: Uji statistik menunjukkan hasil $p$ value $=0,000$, nilai tersebut lebih kecil dari nilai taraf signifikansi yang digunakan yaitu $5 \%$ atau 0.05 , ini berarti bahwa ada pengaruh antara pendidikan kesehatan reproduksi dengan pengetahuan kesehatan organ reproduksi pada siswa tunagrahita dan autisme. Kesimpulan: Pendidikan kesehatan reproduksi berpengaruh terhadap pengetahuan kesehatan organ reproduksi pada siswa tunagrahita dan autisme.
\end{abstract}

Kata kunci: kesehatan reproduksi; tunagrahita; autism

*Corresponding Author: Yuliyanik (email: yulijuju67@yahoo.com) 


\section{Pendahuluan}

Usia remaja merupakan usia yang rawan terhadap perkembangan fisik, mental, sosial juga perkembangan kesehatan reproduksinya (Kementrian Kesehatan RI, 2017; Rokhmah \& Warsiti, 2015). Perubahan ini terjadi pasa semua remaja tanpa terkecuali baik pada remaja normal maupun pada remaja dengan disabilitas (tunagrahita dan autisme) (Farakhiyah et al., 2018; Jaja, 2014). Oleh karena itu pengetahuan dan pelayanan tentang kesehatan reproduksi seksual pada remaja disabilitas yang menginjak dewasa sangatlah penting (Ghazali, 2009).

Remaja yang berkembang secara normal dan remaja dengan disabilitas mengalami hal yang sama pada perkembangan organ reproduksinya (Quint \& O’Brien, 2016), baik pada remaja laki-laki maupun perempuan (Ariantini et al., 2017). Seorang remaja normal dapat memenuhi dan menjaga kesehatan reproduksinya secara mandiri (Altundağ \& Çalbayram, 2016) melalui informasi dari media masa, teman sebaya, orang tua atau tenaga kesehatan (Sari, 2018). Mereka tidak merasa malu dan dapat bertanya atau mencari informasi secara mandiri jika merasa ada gangguan pada kesehatan reproduksinya terutama yang terkait dengan kesehatan organ reproduksinya
(Daniswari et al., 2017). Tetapi pada remaja dengan disabilitas (tunagrahita dan autisme), mereka kurang tanggap (DeBeaudrap et al., 2019) bahkan tidak mengetahui bagaimana menjaga kesehatan reproduksinya terutama kesehatan organ reproduksinya (Ramawati et al., 2012). Bahkan remaja tersebut tidak mengerti apa yang harus dilakukan ketika terjadi perubahan hormonal pada tubuhnya.

Menurut Chou \& Lu, 2012 pada remaja dengan disabilitas perlu ketlatenan dalam memberikan informasi tersebut, harus terus menerus dan sesuai dengan pemahaman mereka (Pakasi \& Kartikawati, 2013). Remaja tersebut harus memahami bahwa hal yang berkaitan dengan kesehatan reproduksi bukanlah hal yang memalukan (Lee et al., 2015). Pengetahuan tentang kesehatan reproduksi sangat diperlukan oleh semua remaja baik itu remaja normal maupun remaja dengan disabilitas (Mardan \& Suarnianti, 2014), karena kematangan kesehatan reproduksi terjadi pada semua remaja. Remaja penyandang disabilitas terkadang terabaikan dalam program kesehatan reproduksi dan seksual, karena dianggap mereka tidak mungkin aktif secara seksual (Addlakha et al., 2017).

Mereka para remaja penyandang disabilitas banyak yang kurang mendapatkan in- 
formasi dasar bagaimana tubuh mereka berkembang (Nugraheni, 2012) dan terjadi perubahan baik secara fisik maupun psikologisnya (Haryono et al., 2013). Beberapa jurnal menulis tentang pengetahuan kesehatan reproduksi, perbedaan penelitian ini adalah untuk meningkatkan pengetahuan dan pemahaman siswa tunagrahita dan siswa autisme dalam pemeliharaan organ reproduksinya. Tujuan dari penelitian ini adalah untuk meningkatkan pengetahuan dan pemahaman siswa tunagrahita dan siswa autisme tentang pemeliharaan kesehatan reproduksi.

\section{Metode}

Desain penelitian yang digunakan dalam penelitian ini adalah menggunakan metode observasi pre - post test dan wawancara (Arikunto, 2013). Populasi yang digunakan dalam penelitian ini adalah seluruh siswa tunagrahita dan siswa autisme yang ada di SMKN 2 Kota Malang, sebanyak 30 orang. Sampel penelitian adalah semua siswa tunagrahita dan siswa autisme yang ada di SMKN 2 Kota Malang sebanyak 30 orang, yaitu total sampling. Instrumen penelitian yang dipakai adalah kuesioner yang diberikan kepada responden. Pengisian kuesioner dilakukan pendampingan pada responden, untuk mem- bantu mereka jika ada hal-hal yang tidak mereka pahami. Kriteria inklusi dalam penelitian ini meliputi semua siswa tunagrahita dan siswa autisme yang datang ke sekolah saat dilakukan penelitian. Kriteria eksklusi adalah siswa normal di sekolah tersebut. Metode pengumpulan data berupa data primer dan data sekunder (Notoadmojo, 2012a). Data primer didapat melalui observasi langsung dan wawancara dengan responden. Data sekunder berasal dari guru koordinator dan kuesioner (Notoadmojo, 2012b). Data diolah dan dianalisa dengan menggunakan SPSS 16 dengan uji Wilcoxon (Dahlan, 2001).

\section{Hasil dan Pembahasan}

Dari data berdasarkan jenis kelamin, didapatkan bahwa jenis kelamin terbanyak adalah siswa laki-laki sebanyak 20 orang $(66,7 \%)$, sedangkan siswa perempuan sebanyak 10 orang (33,3\%). Berdasarkan data usia, usia terbanyak adalah 18 tahun sebanyak 10 orang (33,3\%), sedangkan paling sedikit usia 19 tahun dan 20 tahun, masing-masing sebanyak 4 orang (13,3\%). Siswa terbanyak adalah siswa kelas XII sebanyak 13 orang $(43,3 \%)$, sedangkan paling sedikit siswa kelas $X$ sebanyak 6 orang (20\%). 
Hasil pre test dapat dilihat pada Tabel 1. Tabel 1 didapatkan data, bahwa hasil pre test yang kurang sebanyak 4 orang (13,3\%), hasil cukup sebanyak 21 orang (70\%) dan hasil baik sebanyak 5 orang $(16,7 \%)$.

Hasil post test dapat dilihat pada Tabel 2. Tabel 2 didapatkan data, bahwa hasil post test yang kurang sebanyak 1 orang $(3,3 \%)$, hasil cukup sebanyak 14 orang $(46,7 \%)$ dan hasil baik sebanyak 15 orang (50\%).

Hasil uji statistik dapat dilihat pada Tabel 3. Tabel 3 didapatkan nilai $p=0,00$, dimana nilai $p<0,05$ artinya bahwa ada pengaruh pendidikan kesehatan reproduksi terhadap peningkatan pengetahuan tentang kesehatan reproduksi.

Hasil pre test dari kuesioner yang diberikan kepada responden, didapatkan nilai yang kurang sebanyak 4 orang $(13,3 \%)$, hasil cukup sebanyak 21 orang (70\%) dan hasil baik sebanyak 5 orang $(16,7 \%)$. Hasil pre test yang kurang kemungkinan adalah kurangnya informasi tentang pemeliharaan kesehatan reproduksi yang didapat oleh responden dan juga kurang aktifnya responden mencari informasi tentang kesehatan reproduksi tersebut.

Setelah penyuluhan, dilakukan post test dan hasil yang didapat adalah yang kurang sebanyak 1 orang (3,3\%), hasil cukup sebanyak 14 orang $(46,7 \%)$ dan hasil baik sebanyak 15 orang (50\%). Dari hasil tersebut dapat dilihat bahwa terjadi peningkatan. Responden dengan hasil kurang berubah menjadi baik sebanyak 3 orang, sedangkan responden dengan nilai cukup semuanya berubah menjadi baik. Responden dengan hasil kurang masih ada 1 orang. Hal ini kemungkinan disebabkan oleh pemahaman yang kurang tentang kesehatan reproduksi dari responden tersebut. Perlu bimbingan khusus bagi responden tersebut, agar terjadi peningkatan pemahaman yang nantinya bermanfaat bagi kesehatan reproduksi responden tersebut.

Uji statistik dengan uji Wilcoxon didapatkan $p$ value $=0,00$, dimana nilai $p<0,05$ artinya ada pengaruh pendidikan kesehatan reproduksi terhadap peningkatan pengetahuan tentang kesehatan reproduksi.

Tabel 1. Hasil pre test pada siswa tunagrahita dan siswa autisme

\begin{tabular}{lcccc}
\hline & Frequency & Percent & Valid Precent & Cumulative Precent \\
\hline Valid Kurang (0-3) & 4 & 13.3 & 13.3 & 13.3 \\
Cukup (4-6) & 21 & 70.0 & 70.0 & 83.3 \\
Baik (7-10) & 5 & 16.7 & 16.7 & 100.00 \\
Total & 30 & 100.0 & 100.0 & \\
\hline
\end{tabular}


Pendidikan kesehatan reproduksi ...

Tabel 2. Hasil post test pada siswa tunagrahita dan autisme

\begin{tabular}{lcccc}
\hline & Frequency & Percent & Valid Precent & Cumulative Precent \\
\hline Valid Kurang (0-3) & 1 & 3.3 & 3.3 & 3.3 \\
Cukup (4-6) & 14 & 46,7 & 46,7 & 50 \\
Baik (7-10) & 15 & 50 & 50 & 100.00 \\
Total & 30 & 100.0 & 100.0 & \\
\hline
\end{tabular}

Tabel 3. Hasil Uji Statistik

\begin{tabular}{|c|c|}
\hline & Post Test-Pre Test \\
\hline Z & $-3.606^{\mathrm{a}}$ \\
\hline Asymp.Sig.(2-tailed) & .000 \\
\hline
\end{tabular}

\section{Kesimpulan}

Kesimpulan hasil penelitian ini adalah adanya pengaruh pendidikan kesehatan reproduksi terhadap peningkatan pengetahuan tentang pemeliharaan organ kesehatan reproduksi pada siswa tunagrahita dan siswa autisme.

\section{Daftar Pustaka}

Addlakha, R., Price, J., \& Heidari, S. (2017). Disability and sexuality: Claiming sexual and reproductive rights. Reproductive Health Matters, 25(50), 4-9.

Altundağ, S., \& Çalbayram, N. Ç. (2016). Teaching menstrual care skills to intellectually disabled female students. Molecular Ecology, 25(1314), 1962-1968.

Ariantini, N. S., Kurniati, D. P. Y., \& Duarsa, D. P. (2017). Needs for sexual and reproductive health education for students with hearing impairment in Buleleng District, Bali Province. Public Health and Preventive Medicine Archive, 5(2), 101.

Arikunto, S. (2013). Prosedur Penelitian: Suatu Pendekatan Praktik. Rineka Cipta.
Chou, Y. C., \& Lu, Z. Y. J. (2012). Caring for a daughter with intellectual disabilities in managing menstruation: A mother's perspective. Journal of Intellectual and Developmental Disability, 37(1), 1-10.

Dahlan, M. (2001). Statistik. PT Arkans.

Daniswari, H., Hapsari, E. D., \& Lismidiati, W. (2017). Gambaran Pengalaman Remaja Putri Berkebutuhan Khusus Dalam Menghadapi Menstruasi. Jurnal Persatuan Perawat Nasional Indonesia (JPPNI), 1(1), 52-64.

DeBeaudrap, P., Mouté, C., Pasquier, E., MacSeing, M., Mukangwije, P. U., \& Beninguisse, G. (2019). Disability and access to sexual and reproductive health services in Cameroon: A mediation analysis of the role of socioeconomic factors. International Journal of Environmental Research and Public Health, 16(3), 4-10.

Farakhiyah, R., Raharjo, S. T., \& Apsari, N. C. (2018). Perilaku Seksual Remaja Dengan Disabilitas Mental. Share: Social Work Journal, 8(1), 114.

Ghazali, P. (2009). Pengembangan Buklet Sebagai Media Pendidikan Kesehatan Reproduksi Pada Remaja Cacat Netra. Jurnal 
Kedokteran Dan Kesehatan Indonesia, 1(1), 38-44.

Haryono, T. J. S., Kinasih, S. E., \& Mas'udah, S. (2013). Akses dan Informasi Bagi Perempuan Penyandang Disabilitas Dalam Pelayanan Kesehatan Reproduksi dan Seksualitas. Masyarakat, Kebudayaan Dan Politik, 26(2), 65-79.

Jaja, S. (2014). Bentuk Dan Metode Terapi Terhadap Anak Autisme Akibat Bentukan Perilaku Sosial. Jurnal Edueksos, III(1), 119133.

Kementrian Kesehatan RI. (2017). Pedoman Pelaksanaan Pelayanan Kesehatan Reproduksi bagi Penyandang Disabilitas Usia Dewasa.

Lee, K., Devine, A., Marco, M. J., Zayas, J., GillAtkinson, L., \& Vaughan, C. (2015). Sexual and reproductive health services for women with disability: A qualitative study with service providers in the Philippines. BMC Women's Health, 15(1), 1-11.

Mardan, I. A., \& Suarnianti. (2014). Gambaran Pengetahuan Sikap dan Perilaku Penyandang Distabilitas Tubuh Mengenai Kesehatan Reproduksi di Panti Sosial Bina Daksa Wirajaya (PSBD) Makassar. Jurnal IImiah Kesehatan Diagnosis, 4(2), 189-195.

Notoadmojo, S. (2012a). Metodologi Penelitian Kesehatan. Rineka Cipta.
Notoadmojo, S. (2012b). Promosi Kesehatan dan Perilaku Kesehatan. Rineka Cipta.

Nugraheni, S. (2012). Menguak Belantara Autisme. In Buletin Psikologi Fakultas Psikologi Universitas Gadjah Mada (Vol. 20, Issue nO.1-2, pp. 9-17). Universitas Gajah Mada.

Pakasi, D. T., \& Kartikawati, R. (2013). Between Needs and Taboos: Sexuality and Reproductive Health Education for High School Students. Makara Journal of Health Research, 17(2), 79-87.

Quint, E. H., \& O’Brien, R. F. (2016). Menstrual management for adolescents with disabilities. Pediatrics, 138(1), 1-11.

Ramawati, D., Allenidekania, A., \& Besral, B. (2012). Kemampuan Perawatan Diri Anak Tuna Grahita Berdasarkan Faktor Eksternal dan Internal Anak. Jurnal Keperawatan Indonesia, 15(2), 89-96.

Rokhmah, I., \& Warsiti. (2015). Identifikasi Kebutuhan Kesehatan Reproduksi Bagi Remaja Perempuan Difabel (Tuna Grahita). Kebidanan UNIMUS, 4(1), 39-49.

Sari, M. M. (2018). Gambaran Pengetahuan Orangtua Siswa Tunagrahita Tentang Kesehatan Reproduksi Remaja Tunagrahita Di Slb C Tri Asih Jakarta. Hearty, 6(1). 